\title{
Assessment of the in situ compressive and tensile strength of existing massive hydraulic structures
}

\author{
Frank Spörel ${ }^{1} *$ \\ ${ }^{1}$ Federal Waterways Engineering and Research Institute, Karlsruhe, Germany
}

\begin{abstract}
In Germany hydraulic structures like weirs or locks under the responsibility of the Federal Min-istry of Transport and Digital Infrastructure have an average age of about 80 years. They often show static characteristics, such as construction methods or very large cross sections that are no longer common practice today. When retrofittings are planned new calculations to verify its conformity with stability requirements become necessary. As no adapted regulations have been released for re-assessing the statics of existing solid hydraulic structures a Code of practice has been developed. Compressive and tensile strength derived from concrete cores are decisive input parameters for the calculations. During the last decades concrete cores of more than hundred existing hydraulic structures have been examined by the Federal Waterways Engineering and Research Institute (BAW). These investigations were analysed comprehensively concerning the variation of strength properties and the correlation between compressive and tensile strength in massive hydraulic structures. Furthermore given correlations and factors in technical guidelines which were usually derived by investigations on lab specimen at an age of 28 days were verified concerning their applicability on in situ concrete of old, massive structures. The findings are presented in the paper.
\end{abstract}

\section{Introduction}

The assessment of old structures according to current standards often is not possible. In many cases the structures show static characteristics such as construction methods or very large cross sections that are no longer common practice. As no adapted regulations have been released for re-assessing the statics of existing solid hydraulic structures a Code of practice has been developed by the Federal Waterways Engineering and Research Institute (BAW) [1, 2]. Concrete properties are the technical base for the assessment of the load bearing capacity of existing hydraulic structures. They can be determined by investigations on cores or by an assessment of documents that exist for the structure.

Comprehensive evaluations of numerous tests on concrete cores of hydraulic structures enabled to get an impression on strength properties of the structures depending on the construction period of the last about hundred years. They were the basis for the elaboration of the specifications concerning concrete properties in [1] when an assessment on the basis of documents of the structures is carried out. The background of these specifications is presented in this paper.

\section{Compressive and tensile strength}

\subsection{Correlations in rules and standards}

Besides the compressive strength the tensile strength is an important parameter. As the determination of the axial tensile strength is a complex test the tensile strength is often calculated on the basis of the compressive strength. The calculations for the mean value, the $5 \%$-fractile value and the $95-\%$-fractile value of the tensile strength (Equation 1 to 3 ) can be found in DIN EN 1992-1-1:2011-01 [3].

$$
\begin{aligned}
& f_{c t m}=0.30 * f_{c k}(2 / 3) \\
& f_{c t k, 0,05}=0.7 * f_{c t m} \\
& f_{c t k, 0,95}=1.3^{*} f_{c t m}
\end{aligned}
$$

These equations are valid for water stored cylindrical specimen with a height-to-diameter-ratio (h/d-ratio) of 2.0 for the compressive strength test. They can be traced back to evaluations of literature data and investigations of Heilmann in 1969 on concrete at an age of 28 days [4]. Based on the mean compressive strength of concrete cubes with a side length of $200 \mathrm{~mm}$ the correlation was determined for mean values of the tensile strength (Equation 4, Figure 1).

$$
\beta_{Z}=c^{*} \beta_{D}^{(2 / 3)}
$$

* Corresponding author: frank.spoerel@baw.de 
$\beta_{Z} \quad$ mean axial tensile strength at an age of 28 days in $\mathrm{kp} / \mathrm{cm}^{2}$

$\beta_{D} \quad$ mean compressive strength of a concrete cube with a side length of $200 \mathrm{~mm}$, immersed in water at $20^{\circ} \mathrm{C}$ for 7 days, stored at $20^{\circ} \mathrm{C}$ in a relative humidity of $65 \%$ until testing in $\mathrm{kp} / \mathrm{cm}^{2}$

c

coefficient $\left(\mathrm{c}_{\min }=0.36, \mathrm{c}_{\text {mean }}=0.52, \mathrm{c}_{\max }=0.68[4]\right)$

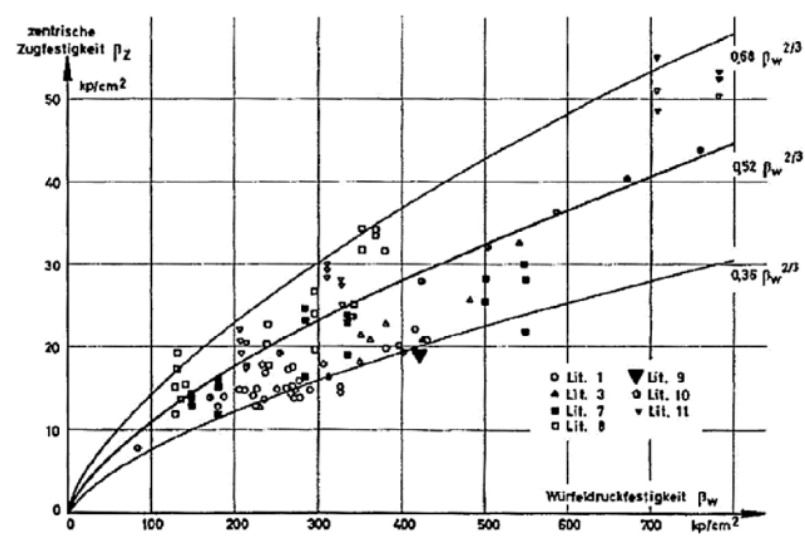

Fig. 1: Correlation between axial tension and compressive strength of dryly stored cubes with a side length of $200 \mathrm{~mm}$ [4]

Due to the different development of the compressive and tensile strength it is pointed out that at different ages different correlations may be expected [4]. Hence for existing structures this remark also has to be considered. The transferability of that correlation is considered critically by [5] as well. The tensile strength of existing structures should be assessed carefully.

To convert equation 4 which was determined for cubes with a side length of $200 \mathrm{~mm}$ in $\mathrm{kp} / \mathrm{cm}^{2}$, dryly stored according to equation 4 , to water stored cylinders with a h/d-ratio of 2.0 in $\mathrm{N} / \mathrm{mm}^{2}$ conversion factors regarding specimen size and storage conditions are necessary. According to [6] a conversion by equation 5 is valid for strength classes between $\mathrm{C} 20 / 25$ and C50/60. Based on [4] the conversion results in equation (6).

$$
f_{c t} * c 1=0.52 *\left(f_{c} * c 1 /(c 2 * c 3 * c 4)\right)^{(2 / 3)}
$$

c1 $10\left(\right.$ Conversion $\mathrm{N} / \mathrm{mm}^{2}$ to $\left.\mathrm{kp} / \mathrm{cm}^{2}\right)$

c2 1.05 (Conversion cube side length $200 \mathrm{~mm}$ to cube side length $150 \mathrm{~mm}$ )

c3 0.92 (Conversion dry storage to wet storage according to DIN 1045-2)

0.82 (Conversion cube specimen to cylinder specimen $\mathrm{h} / \mathrm{d}=2.0$ )

$$
f_{c t}=0.28 *\left(f_{c}\right)^{(2 / 3)}
$$

Equation 6 resembles equation 1 which was introduced to CEB fib Model Code 1978 [7] in conjunction with equations 2 and 3 . The origin for the replacement of the mean compressive strength according to equation 4 to the characteristic compressive strength according to equation 1 could not be reconstructed by literature research.
Calculating the ratios of $\mathrm{c}_{\min }$ and $\mathrm{c}_{\text {mean }}$ respectively $\mathrm{c}_{\max }$ and $\mathrm{c}_{\text {mean }}$ according to equation 4 and figure 1 the following results are obtained.

$$
\begin{aligned}
& c_{\text {min }} / c_{\text {mean }}=0.36 / 0.52=0.69 \\
& c_{\text {max }} / c_{\text {mean }}=0.68 / 0.52=1.31
\end{aligned}
$$

These ratios match the ratios between $f_{c t k ; 0.05}$ and $f_{c k}$ respectively $f_{\text {ctk; } 0.95}$ and $f_{\text {ck }}$ according to equations 2 and 3 . These considerations hypothesize that equations 1 to 3 are based on the investigations of [4] with the exception that the mean compressive strength was replaced by the characteristic compressive strength.

\subsection{Evaluation of existing structures}

When evaluating existing structures the concrete properties are different from the properties at an age of 28 days of laboratory specimen. As the evaluation of existing structures becomes more and more important the activities concerning concrete properties of existing structures have increased and methods to handle them were summarised and guidelines for the assessment of existing structures have been developed [8, 9, 10, 11]. As the basis for equation 1 are laboratory tests the correlation represents the laboratory tensile strength and not the in situ tensile strength [12]. Recent investigations have reasoned that equation 1 is also suitable for the estimation of the tensile strength of existing structures [9]. In cases with a particular importance of the tensile strength the determination of the tensile strength nevertheless is recommended.

Long term experience of the BAW by assessments of existing hydraulic structures revealed that there might be different correlations between compressive and tensile strength of the concrete of old hydraulic structures compared to the correlations in [3] for newly build structures. This seemed comprehensible regarding different developments of compressive and tensile strength over time or the temperature development due to heat of hydration in the massive structures.

\section{Existing Hydraulic structures}

The Federal Waterways and Shipping Administration of Germany (WSV) is responsible for 317 locks and 256 weirs [13]. The age of the structures varies in a wide range. There are newly built structures and structures with an age up to more than hundred years. Especially the concrete properties of old structures have been investigated in the past in the course of expertises of the BAW on the condition of the structures. Many concrete cores were taken and investigated concerning compressive and splitting tensile strength. By a comprehensive analysis of the data a good survey on properties of concrete for massive hydraulic structures in the course of time is obtained. 


\section{Analysis of investigations on concrete cores of hydraulic structures}

\subsection{Objective of the analysis}

During the assessments of the concrete properties for many structures by the BAW during the last about thirty to forty years it was observed that the tensile strength often was lower than expected compared to the correlation of equations 1 and 2 .

For that purpose the data was comprehensively evaluated to investigate if these observations of the single structures showed systematic tendencies concerning the correlation between compressive and tensile strength. The results of these analyses were used to determine specifications in the code of practice [1].

\subsection{Preparation of the data}

The strength values of the single investigations were obtained by tests on concrete cores with different length, diameters and storage. The axial tensile strength was determined by the splitting tensile strength test and calculated according to [3] (equation 7).

$$
f_{c t}=0.9 * f_{c t, s p}
$$

To obtain comparable results for the compressive strength the results had to be converted to a reference specimen size and storage. According to [3] this is a wet stored cylindrical specimen with a h/d-ratio of 2.0 . Usually the compressive strength is determined by core specimen with a diameter between 100 and $150 \mathrm{~mm}$ and a h/d-ratio of 1.0. The test results were converted according to equation 8 .

$$
f_{c, 2.0}=f_{c}, 1.0 * 0.82
$$

$\mathrm{f}_{\mathrm{c}, 2.0} \quad$ compressive strength, $\mathrm{h} / \mathrm{d}$-ratio 2.0

\section{$\mathrm{f}_{\mathrm{c}, 1.0} \quad$ compressive strength, $\mathrm{h} / \mathrm{d}$-ratio 1.0}

The cores for the compressive strength test were usually stored in laboratory climate of $20^{\circ} \mathrm{C}$ and $65 \%$ relative humidity for a few days before testing, referred to as dryly stored. As the moisture of the specimen has influence on the test result the specimen generally should be tested in a comparable moisture state as in the structure. This is complicated as during the transportation and storage of the cores until preparation and by sawing and grinding the moisture content is always changed in an undefined way depending on the concrete quality and the storage. To account for influences of the moisture content the results were converted according to equation 9 .

$$
f_{c, w e t}=f_{c, d r y} * 0.92
$$

Besides mean values the standard deviation and the coefficient of variation (COV) were determined. Characteristic strength values were calculated according equation 10 [1] based on a log-normal distribution of the test results and a level of confidence of $95 \%$.

$$
X_{k}=\exp \left(m_{y}-k_{n}{ }^{*} s_{y}\right)
$$

$$
\begin{aligned}
& m_{y}=1 / n * \sum \ln \left(x_{i}\right) \\
& s_{y}=\sqrt{ } 1 /(n-1)^{*} \sum\left(\ln \left(x_{i}\right)-m_{y}\right)^{2} \\
& k_{n} \text { according to table } 1
\end{aligned}
$$

Table 1. kn, dependant on specimen number $\mathrm{n}[1]$

\begin{tabular}{|c|c|c|c|c|c|c|c|c|c|c|c|c|c|}
\hline $\mathrm{n}$ & 3 & 4 & 5 & 6 & 7 & 8 & 10 & 15 & 20 & 50 & 100 & 200 & 500 \\
\hline $\mathrm{k}_{\mathrm{n}}$ & 6.36 & 4.65 & 3.94 & 3.54 & 3.28 & 3.10 & 2.86 & 2.54 & 2.38 & 2.06 & 1.93 & 1.84 & 1.76 \\
\hline
\end{tabular}

\subsection{Compressive and tensile strength over time}

Figure 2 summarises the mean compressive strength which was determined on numerous hydraulic structures constructed during the last century. Each point represents a mean compressive strength evaluated for single parts of the different structures like for example lock chamber walls, baseplates of locks or weir piers.

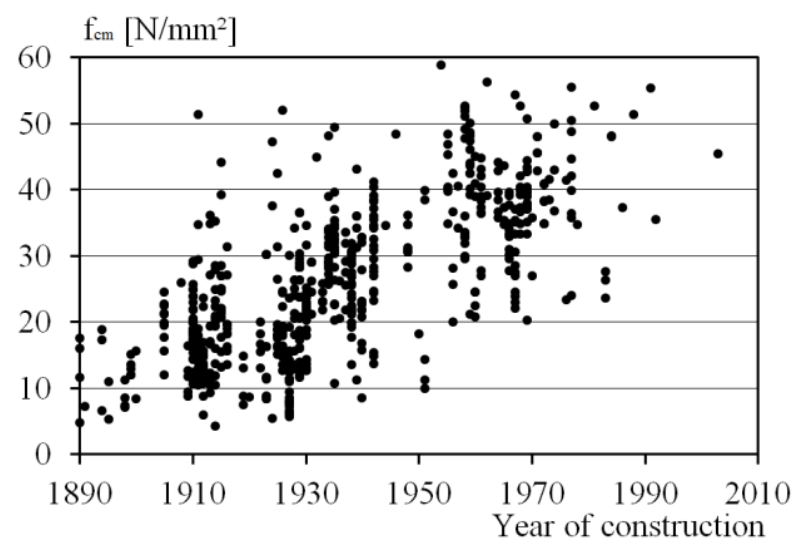

Fig. 2: Mean compressive strength of hydraulic structures

Figure 3 shows the same correlation for the axial tensile strength determined by splitting tensile strength tests and calculated according to equation 7 .

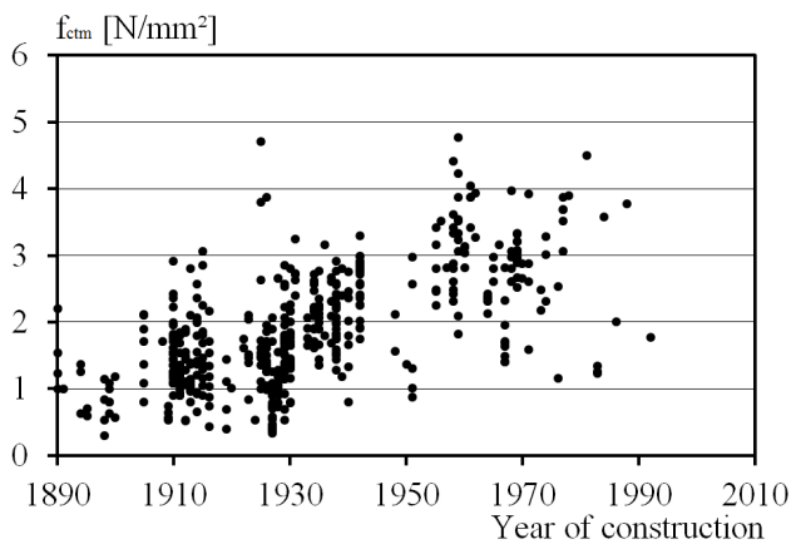

Fig. 3: Mean tensile strength of hydraulic structures

The results give a good survey on the development and the spread of the mean compressive strength of hydraulic structures over time. The spread of the results may also result from the fact that sometimes repair concrete in the structures could not be traced back to the year of repair as this was unknown. High strength results in old structures might result from these uncertainties. 
Furthermore it becomes apparent that many structures have a very low strength which is not covered by the strength classes according to [3].

\subsection{Statistical data of strength properties}

The assumed coefficient of variation (COV) of the compressive strength in current standards can be derived from equation 11 which describes the correlation between mean and characteristic compressive strength according to [3].

$$
f_{c m}=f_{c k}+8
$$

Provided that $\mathrm{f}_{\mathrm{ck}}$ represents the 5-\%-quantile of a normal distribution equation 12 is valid.

$$
f_{c k}=f_{c m}-1,645^{*} \sigma_{c}
$$

These two equations imply a standard deviation $\sigma_{\mathrm{c}}=4.86 \mathrm{~N} / \mathrm{mm}^{2}$. The COV for the strength classes can be calculated with the assumption of a standard deviation of 4.86 independently of the strength level (Equation 13).

$$
C O V_{c}=4.86 / f_{c m}
$$

Rüsch et. al. [14] investigated the variation of the results of the compressive strength of cube specimen. The results were based on an international survey. The standard deviation of the compressive strength could be described by equation 14 .

$$
\begin{gathered}
\sigma_{\text {cube200 }}=1 /\left(0.0197+319 /\left(f_{\text {cm,cube } 200}\right)^{2}\right) \\
\sigma_{\text {cube200 }} \text { Standard deviation }\left[\mathrm{kp} / \mathrm{cm}^{2}\right] \\
f_{\text {cm,cube } 200} \text { dryly stored cube }\left[\mathrm{kp} / \mathrm{cm}^{2}\right]
\end{gathered}
$$

A transformation considering units, specimen and storage conditions by the transformation factors $\mathrm{c} 1$ to $\mathrm{c} 4$ of equation 5 results to equation 15 .

$$
\sigma_{\mathrm{c}}=0.79 /\left(0.197+31.9 /\left(\mathrm{f}_{\mathrm{cm}} / 0.79\right)^{2}\right)
$$

Figure 4 shows the standard deviation according to [3] and the transformed correlation according to Rüsch (equation 15) and in figure 5 the same data is expressed as the resulting COV. Additionally the data from the investigated structures are added.

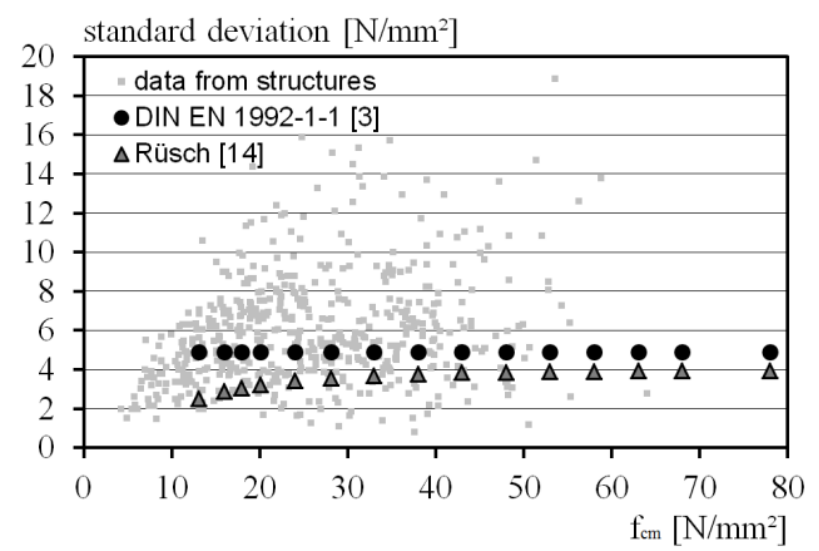

Fig. 4: Standard deviation for the compressive strength

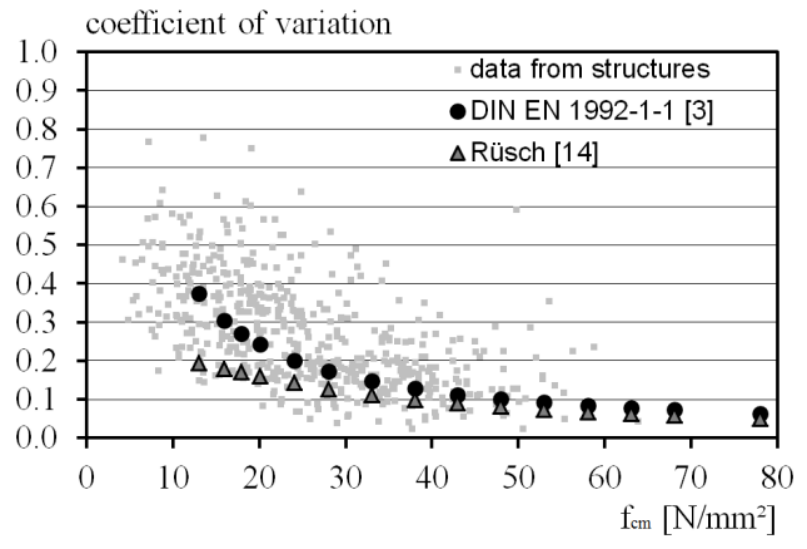

Fig. 5: COV for the compressive strength

The figures show similar values for both approaches for compressive strengths of more than $30 \mathrm{~N} / \mathrm{mm}^{2}$ and clearly indicate rising COVs for low strength concrete. The fundamental correlation of the equations is visible as well as the high scatter of the results. As the correlations according to [3] and [14] are based on lab specimen it is comprehensible that at the structures often higher COVs occur. Besides the variability of the concrete production influences of workmanship and long term exposure of the concrete have to be considered. Furthermore the massive hydraulic structures are exposed to heat of hydration at early age. This may have additional influence as observed in [15].

The same considerations for the tensile strength, assuming that $f_{\text {ctk }}$ represents the 5-\%-quantile of a normal distribution, results in equation 16. Equations 17 and 18 can be deduced by equations 2 and 16 .

$$
\begin{gathered}
f_{c t k, 0,05}=f_{c t m}-1,645^{*} \sigma_{c t} \\
\sigma_{c t}=0,182 * f_{c t m} \\
C O V_{c t}=0,182
\end{gathered}
$$

A Comparison of equation 13 and 18 hypotheses that [3] assumes different dependencies of the COV of the compressive and the tensile strength. Whereas the fundamental correlation for the compressive strength has been shown in [14] the basis for the tensile strength could not be reconstructed by literature research. In [12] a similar order of the COV for the tensile strength as for the compression strength was detected.

Data from the structures is presented in figure 6 and 7. The tensile strength is based on splitting tensile strength tests and converted according to equation 7 .

The figures show that standard deviation and COV depend on the mean tensile strength. With rising strength the standard deviation rises and the COV decreases. The COV indicates a similar order for the tensile and compressive strength. This was observed by [12] as well. Especially for low strength concrete the correlations assumed in [3] undervalues the results of the structures. For the COV of the tensile strength this is more obvious than for the compressive strength. 
standard deviation $\left[\mathrm{N} / \mathrm{mm}^{2}\right]$

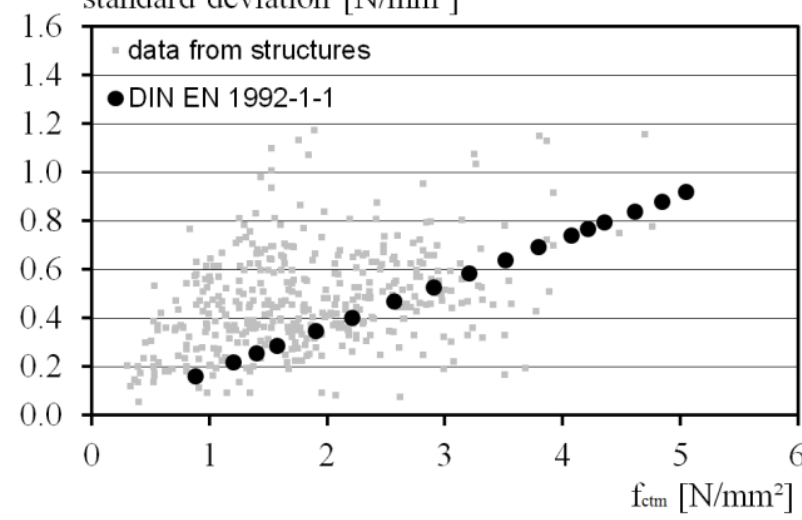

Fig. 6: Standard deviation for the tensile strength

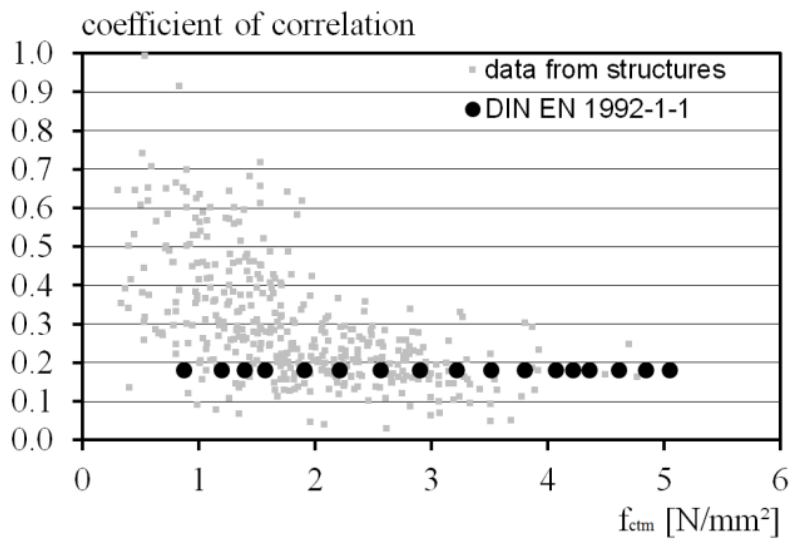

Fig. 7: COV for the tensile strength

Due to the different correlations of the standard deviation and the COV for compressive and tensile strength the correlations in [3] cannot sufficiently assess the concrete of the existing hydraulic structures.

As the standard deviation and the COV mainly have influence on the characteristic values $\mathrm{f}_{\mathrm{ck}}$ and $\mathrm{f}_{\mathrm{ctk}}$ the data of the structures indicate that a calculation of tensile strength properties based on the compressive strength according to equations 1 to 3 seems not recommendable.

\subsection{Verification of conversion factors}

For the comprehensive analysis of the assessments of hydraulic structures the conversion factors for shape and storage influence became significant. During the recent assessment of a weir the opportunity to verify some conversion factors could be realised. The weir was constructed in 1935 with a maximum grain size of about $50 \mathrm{~mm}$. The compressive strength test based on 235 specimens revealed a mean compressive strength $f_{c m}$ of $44 \mathrm{~N} / \mathrm{mm}^{2}$. The results of the investigations for the $\mathrm{h} / \mathrm{d}-$ ratio and moisture are given in table 2 . Only results of vertical cores are considered. For the comparison of the dry (laboratory climate) and wet condition specimen of the same area of the structure were evaluated.

The results show that independently of the storage condition and the core diameter the $\mathrm{h} / \mathrm{d}$-ratio is less than assumed in equation 8 . The results vary between 0.70 for a core diameter of $100 \mathrm{~mm}$ and 0.74 and 0.77 for a core diameter of $150 \mathrm{~mm}$. The validity of equation 8 depends on many factors. A comprehensive compilation of international research concerning the influence of the shape on compressive strength can be found in [16]. Being aware of the scatter of these numerous investigations and the results in table 2 it is clear that equation 8 can only be a rough estimation of that correlation.

Table 2. Influence of shape and storage condition on in situ compressive strength of a weir.

\begin{tabular}{|c|c|c|c|c|c|}
\hline Diameter & shape & condition & $\begin{array}{l}\text { Mean compressive } \\
\text { strength }\end{array}$ & $\mathrm{n}$ & ratio \\
\hline \multirow{8}{*}{150} & $\mathrm{~h} / \mathrm{d}=2$ & \multirow{2}{*}{ Dry } & 46.1 & 36 & \multirow{2}{*}{0.77} \\
\hline & $\mathrm{h} / \mathrm{d}=1$ & & 60.2 & 57 & \\
\hline & $\mathrm{h} / \mathrm{d}=2$ & \multirow{2}{*}{ Wet } & 40.3 & 5 & \multirow{2}{*}{0.74} \\
\hline & $\mathrm{h} / \mathrm{d}=1$ & & 54.6 & 13 & \\
\hline & \multirow{2}{*}{$\mathrm{h} / \mathrm{d}=1$} & Wet & 54.6 & 13 & \multirow{2}{*}{0.89} \\
\hline & & Dry & 61.3 & 13 & \\
\hline & \multirow{2}{*}{$h / d=2$} & Wet & 40.3 & 5 & \multirow{2}{*}{0.87} \\
\hline & & Dry & 46.2 & 5 & \\
\hline \multirow{2}{*}{100} & $\mathrm{~h} / \mathrm{d}=2$ & \multirow{2}{*}{ Dry } & 46.8 & 6 & \multirow{2}{*}{0.70} \\
\hline & $\mathrm{h} / \mathrm{d}=1$ & & 67.0 & 11 & \\
\hline 150 & \multirow{2}{*}{$h / d=1$} & \multirow{2}{*}{ Dry } & 58.2 & 7 & \multirow{2}{*}{0.87} \\
\hline 100 & & & 67.0 & 11 & \\
\hline 150 & \multirow{2}{*}{$h / d=2$} & \multirow{2}{*}{ Dry } & 46.2 & 5 & \multirow{2}{*}{0.99} \\
\hline 100 & & & 46.8 & 6 & \\
\hline
\end{tabular}

The ratio of the storage condition is less than in equation 9 as well with ratios of 0.87 and 0.89 . Furthermore the core diameter had an influence on the results depending on the $\mathrm{h} / \mathrm{d}$-ratio. Whereas for the $\mathrm{h} / \mathrm{d}$ ratio of 2.0 no influence was detected $(0.99)$ the results with the $\mathrm{h} / \mathrm{d}$-ratio of 1.0 revealed a remarkable higher compressive strength for the specimen with a diameter of $100 \mathrm{~mm}$. This observation seems to be confirmed by investigations on the influence of core diameter on the compressive strength of concrete elements published by Henzel [17]. Cores with a diameter of $100 \mathrm{~mm}$ with a $\mathrm{h} / \mathrm{d}$-ratio of 1.0 revealed about $5 \%$ and cores with a diameter of $50 \mathrm{~mm}$ about $10 \%$ higher compressive strength results than cores with a diameter of $150 \mathrm{~mm}$.

\subsection{Characteristic strength values}

\subsubsection{Requirements and Assumptions}

Besides the aforementioned conversion factors the compressive strength of cores may differ from the cube strength. This is considered by a conversion factor which is described in detail in [9]. The original work of Petersons [18] indicates that this conversion might depend on the strength level itself. A wide scatter was also observed in [15]. Recalling these findings and the aforementioned considerations concerning specimen shape and storage condition the choice of a statistical method to determine the characteristic values entails 
another influencing parameter. Different evaluation methods have been applied [1, 19-22].

In [21] a level of confidence of about $75 \%$ is stated for the determination of characteristic values. But according to $[23,24]$ the level of confidence in [21] is lower. For the assessment of the load bearing capacity of existing hydraulic structures it was decided to choose a higher level of confidence in [1]. The determination of the characteristic value according to equation 10 is based on [21] but with an adapted level of confidence of $95 \%$ for the $5 \%$-quantile. Therefore an application of [20] was excluded as this method leads to the experience of the assessments of existing hydraulic structures to a systematic overestimation of the real characteristic value which was observed by [25-27] as well. The method according to [22] is excluded as it in fact reduces the overestimation compared to [20] but still systematically overestimates the characteristic strength values.

\subsubsection{Compressive and tensile strength}

Figures 8 and 9 show the correlation between mean and characteristic values of the compressive and tensile strength of the data of the structures evaluated according to equation 10. The characteristic values are mostly lower than the assumption according to [3]. Considering the high COVs (Figure 5) and the high level of confidence of equation 10 this seems comprehensible.

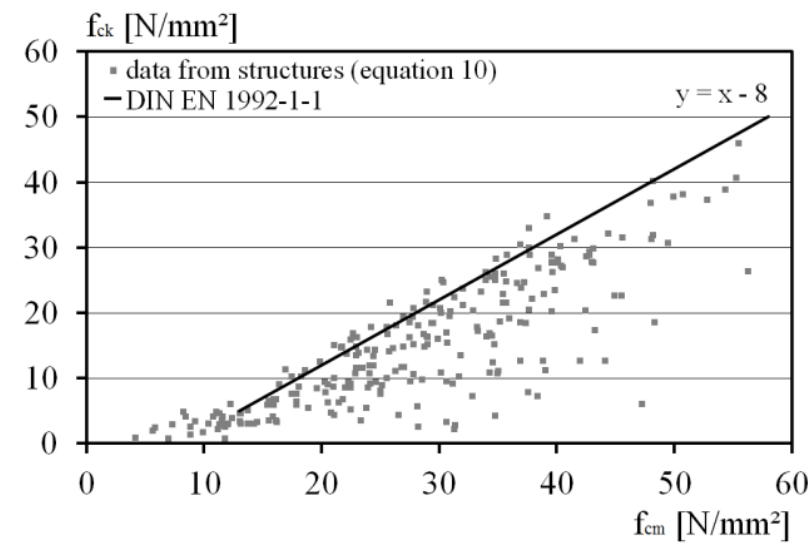

Fig. 8: Correlation between $f_{c m}$ and $f_{c k}$ according to [3] and equation 10

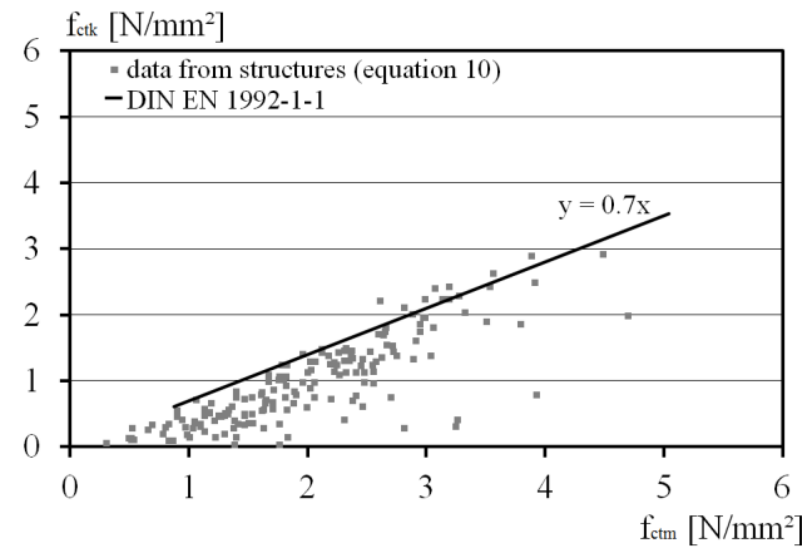

Fig. 9: Correlation between $\mathrm{f}_{\mathrm{ctm}}$ and $\mathrm{f}_{\mathrm{ctk}}$ according to [3] and equation 10
Figures 8 and 9 confirm that the estimation of the characteristic strength values according to equations 2 and 11 do not lead to conservative results for the assessment of existing structures. Basis for figures 8 and 9 is a level of confidence of $95 \%$ as mentioned before. Applying the procedure of DIN EN 1990 [21] leads to a slight approach as can be seen in figure 10 .

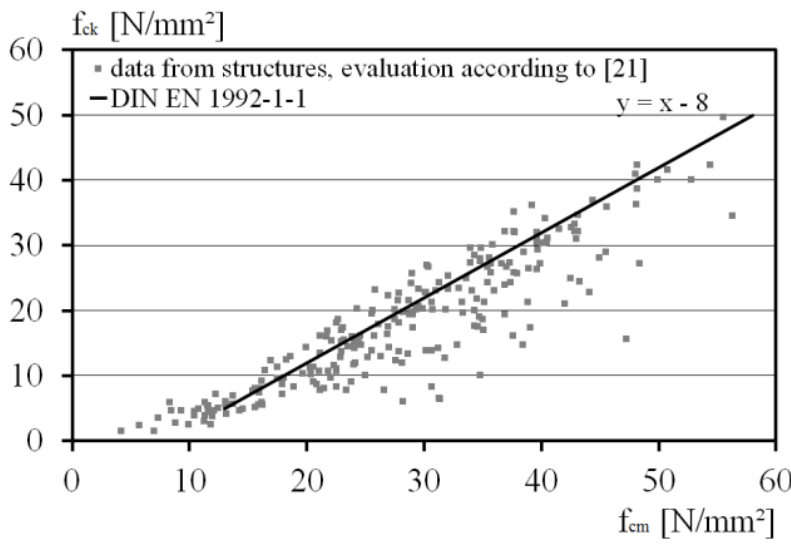

Fig. 10: Correlation between $\mathrm{f}_{\mathrm{cm}}$ and $\mathrm{f}_{\mathrm{ck}}$ according to [3] and an evaluation of $f_{\text {ck }}$ according to [21]

Still the evaluation is not on the conservative side. A fitting procedure would allow for an assessment of the level of confidence which forms the basis of equations 2 and 11 .

\subsection{Correlation between compressive and tensile strength}

The aim of the evaluations was to verify if equations 1 and 2 are applicable to the assessment of existing structures. Figure 11 shows the correlation between the mean compressive and tensile strength and the correlation according to [3] based on equations 1 and 11 . Additionally the correlations according to [4] (Figure 1, equations 4 and 6 ) are added as they were originally based on mean values. The data shows that the correlation of [3] covers the mean of the data for the structures. The correlations of [4] cover the upper spread of the data but do not include the lower spread.

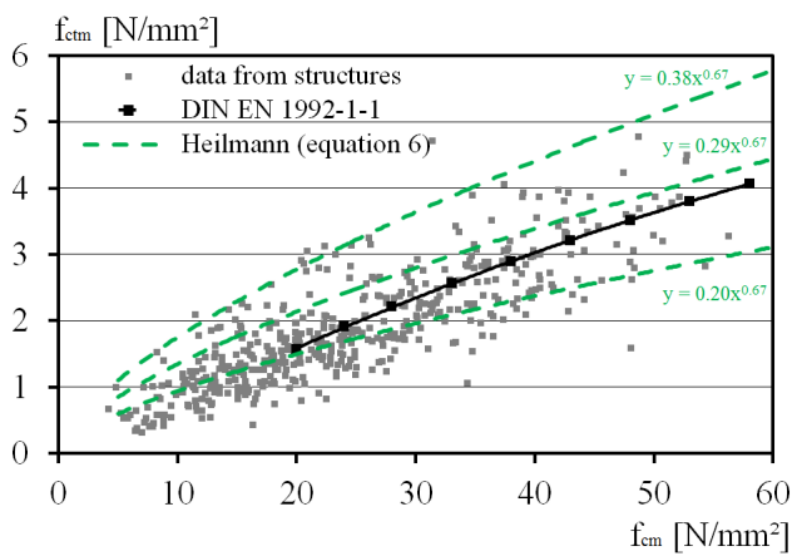

Fig. 11: Correlation between $\mathrm{f}_{\mathrm{cm}}$ and $\mathrm{f}_{\mathrm{ctm}}$

When comparing characteristic values the COVs and the applied statistical method has a decisive impact on 
the transferability of the equations of [3] to the data. This influence gets even more dominant if mean and characteristic values are compared as for example in equation 1. Figure 12 shows the verification of equation 1 with data from the structures based on compressive strength tests for $\mathrm{f}_{\mathrm{ck}}$ and splitting tensile tests for $\mathrm{f}_{\mathrm{ctm}}$.

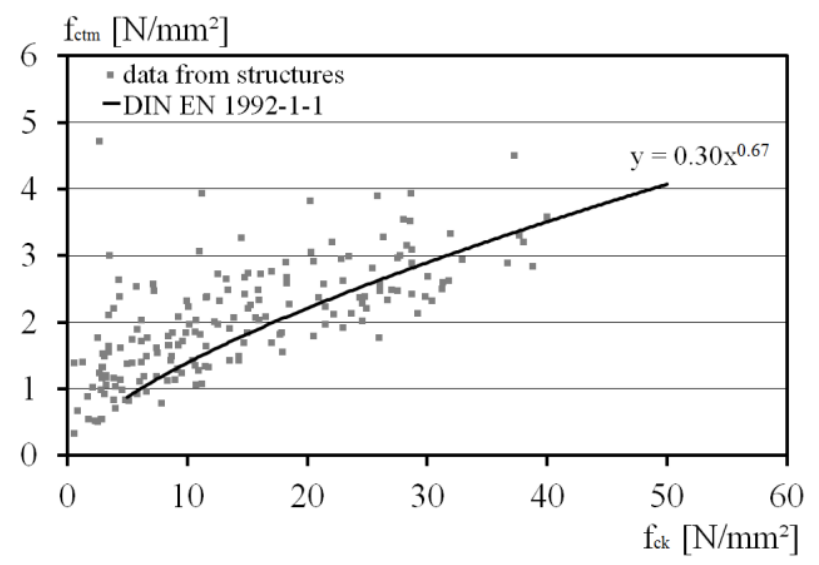

Fig. 12: Correlation between $f_{c k}$ and $f_{c t m}$

The mean tensile strength based on splitting tensile tests in most of the cases is higher than calculated from the characteristic compressive strength. Considering the $\mathrm{COV}$ of the compressive strength which in many cases is higher than assumed by [3] (Fig. 5) and the influence of the level of confidence for the determination of characteristic values (Fig. 9, Fig. 10) the results of figure 12 are comprehensible.

The correlation for equation 2 is illustrated in figure 13. The analysis of characteristic values for compressive and tensile strength reveals that the characteristic tensile strength is overvalued in most cases by equation 2 .

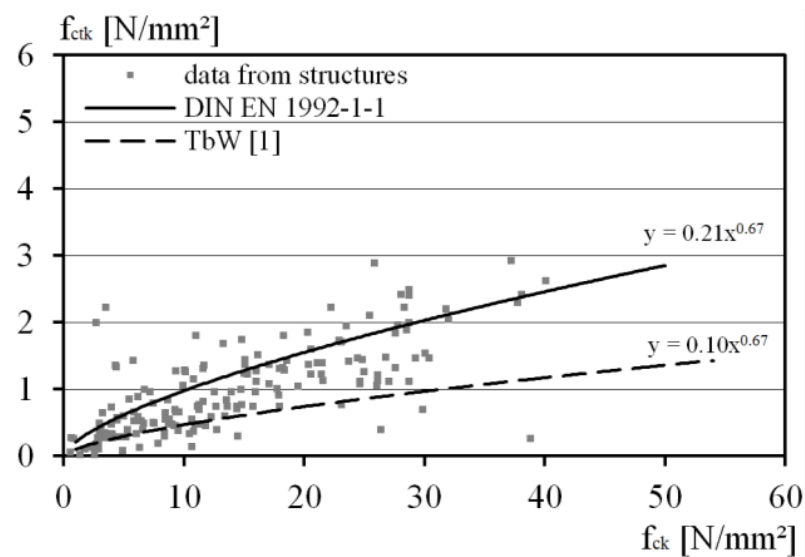

Fig. 13: Correlation between $f_{c k}$ and $f_{c t k}$

For that reason equation 19 was derived from figure 13 with the aim that it covers most of the results conservatively.

$$
f_{c t k, i s}=0.10 * f_{c k, i s}(2 / 3)
$$

\subsection{Application of the findings in a Code of Practice (TbW)}

The Code of Practice: Assessment of the load bearing capacity of Existing Solid Hydraulic Structures (TbW)
[1] offers the opportunity to assess the concrete properties on the basis of documents of the structure. These documents may give information on the year of construction and historical strength classes that were used for the construction. The characteristic compressive strength which can be assigned to the historical strength classes was determined in [8] and adapted in [1]. In [8] the tensile strength however is assumed to follow the correlations of [3]. As the experience on old hydraulic structures revealed different results for the code of practice [1] the tensile strength was considered separately based on equation 19 .

An application of equation 2 does not seem adequate as most of the results of the characteristic tensile strength are lower than calculated by equation 2 . When assessing the load bearing capacity of existing hydraulic structures exclusively on the basis of documents equation 2 does not produce conservative results.

\section{Summary}

The age of hydraulic structures in Germany varies in a wide range. There are newly built structures and structures with an age up to more than hundred years. Especially the concrete properties of old structures have been investigated in the past in the course of expertises of the BAW on the condition of the structures. In many cases the structures show static characteristics such as construction methods or very large cross sections that are no longer common practice. Many structures consist of different concrete layers with a higher concrete quality for the exposed surface and a minor concrete quality for the massive concrete. Due to different concrete layers and long-term exposure, resulting in carbonation or freeze-thaw damage of the concrete surface, nondestructive tests to assess the compressive strength as for example proposed in [28] are often not applicable.

For the reassessment of an existing structure the knowledge of the compressive strength is essential. The tensile strength often is calculated based on the compressive strength. The bases for these calculations are investigations on lab specimen which were conducted many years ago. The transferability of these calculations for the assessment of existing structures was verified. Numerous investigations on cores of existing structures were analysed and an adjusted method for existing structures was determined. The results and the background of these regulations for a Code of practice for the assessment of the load bearing capacity of existing hydraulic structures [1] are presented.

\section{References}

1. BAW Code of Practice: Assessment of the load bearing capacity of Existing Solid Hydraulic Structures (TbW). Federal Waterways Engineering and Research Institute (2016).

2. Proceedings: BAWKolloquium Nachrechnung von (massiven) Wasserbauwerken. Federal Waterways Engineering and Research Institute (2015) 
3. DIN EN 1992-1-1:2011-01 Eurocode 2: Design of concrete structures - Part 1-1: General rules and rules for buildings; German version EN 1992-1$1: 2004+$ AC:2010 (2011)

4. H. G. Heilmann: Beziehungen zwischen Zug- und Druckfestigkeit des Betons. Beton 19, No. 2, pp.6870 (1969)

5. H. Rüsch: Die Ableitung der charakteristischen Werte der Betonzugfestigkeit. Beton 25, No. 2, pp. 55-58 (1975).

6. V. Malárics: Ermittlung der Betonzugfestigkeit aus dem Spaltzugversuch an zylindrischen Betonproben. Karlsruher Reihe Massivbau, Baustofftechnologie, Materialprüfung 69, $\mathrm{PhD}$ thesis (2010)

7. CEB-FIP Model Code for concrete structures. International System of Unified Standard Codes of Practice for Structures (1978).

8. J. Schnell, K. Zilch, D. Dunkelberg, M. Weber: Sachstandbericht Bauen im Bestand - Teil I: Mechanische Kennwerte historischer Betone, Betonstähle und Spannstähle für die Nachrechnung von bestehenden Bauwerken. DAfStb-Heft No. 616 (2016)

9. N. Brauer et. al.: Sachstandbericht Bauen im Bestand - Teil II: Bestimmung charakteristischer Betondruckfestigkeiten und abgeleiteter Kenngrößen im Bestand. DAfStb-Heft No. 619 (2017)

10. Richtlinie zur Nachrechnung von Straßenbrücken im Bestand, BMBS Berlin/Bonn (2011)

11. Assessment of In-situ Compressive Strength of Concrete. Guide to good practice, German Society for Concrete and Construction Technology (DBV), 2016

12. F. S. Rostásy, E.-H. Ranisch: Altersabhängige Beziehung zwischen der Druck- und Zugfestigkeit von Beton im Bauwerk - Bauwerkszugfestigkeit. DAfStb-Heft No. 408 (1990)

13. J. Bödefeld, K. Kloé: Management system for infrastructures at waterways. Proceedings of the Third International Symposium on Life-Cycle Civil Engineering (IALCCE'12) (2013)

14. H. Rüsch et. al.: Statistische Analyse der Betonfestigkeit. DAfStb-Heft No. 207 (1969)

15. The Concrete Society: In situ strength of concrete. An investigation into the relationship between core strength and standard cube strength. Project Report No. 3, (2004)

16. J. Bonzel: Zur Gestaltsabhängigkeit der Betondruckfestigkeit. Beton- und Stahlbetonbau, 54, pp. 223-228, pp. 247-248, (1959)
17. J. Henzel, W. Freitag: Zur Ermittlung der Betondruckfestigkeit im Bauwerk mit Hilfe von Bohrkernen kleineren Durchmessers Beton 19, No. 4, pp.151-155 (1969)

18. N. Petersons: Should standard cube test specimens be replaced by test specimens taken from structures. Materials und Structures, 5, pp. 425-435 (1968)

19. DIN 1048-4: Prüfverfahren für Beton Bestimmung der Druckfestigkeit von Festbeton in Bauwerken und Bauteilen Anwendung von Bezugsgeraden und Auswertung mit besonderen Verfahren. (1991)

20. DIN EN 13791:2008-05: Assessment of in-situ compressive strength in structures and precast concrete components; German version EN 13791:2007

21. DIN EN 1990:2010-12: Eurocode: Basis of structural design; German version EN 1990:2002 + $\mathrm{A} 1: 2005+\mathrm{A} 1: 2005 / \mathrm{AC}: 2010$

22. DIN EN 13791/A20:2017-02: Assessment of in-situ compressive strength in structures and precast concrete components; Amendment A20

23. Fischer, L.: Europäische Baunormen im Test Charakteristische Werte nach DIN EN 1990, DIN EN 1926 und DIN EN 13162. Bautechnik, 83, pp. 351-364, (2006)

24. Schäper, M.: Zur Anwendung der logarithmischen Normalverteilung in der Materialprüfung - Missverständliche Normaussagen ergeben fehlerhafte Nachweise. Bautechnik, 87, pp. 541-549 (2010)

25. M. Holicky, K. Jung, M. Sykora: Comparison of methods for estimation of concrete strength. Proceedings: Safety, reliability and risk analysis: Theory, methods and applications, pp. 1629-1633, (2009)

26. M. Loch, F. Stauder, J. Schnell: Bestimmung der charakteristischen Betonfestigkeit in Bestandstragwerken - Grenzen von DIN EN 13791. Beton und Stahlbetonbau 106, No. 12, pp. 804-813 (2011)

27. R.D.J.M. Steenbergen, A.H.J.M. Vervuurt: Determining the in situ concrete strength of existing structures for assessing their structural safety. Structural Concrete 13, No. 1, pp. 27-31 (2012)

28. D. Breysse: Non-Destructive Assessment of Concrete Structures: Reliability and Limits of Single and Combined Techniques. State-of-the-Art Report of the RILEM Technical Committee 207-INR (2012) 